\title{
Peroxiredoxin 4: a multifunctional biomarker worthy of further exploration
}

\author{
Janin Schulte
}

\begin{abstract}
Currently, there is much interest in identifying clinically relevant biomarkers, as they have the potential to be high utility non-invasive tools for early diagnosis and reliable patient monitoring in numerous conditions. Since its discovery almost 15 years ago, research on the ubiquitous antioxidant enzyme peroxiredoxin 4 (Prx4) has culminated in the recognition that Prx4 levels are different in blood drawn from the healthy general population and patients with acute or chronic diseases. In this commentary, the most striking research data from different in vitro approaches, animal models and human observational studies are discussed collectively, highlighting the clinical importance of Prx4 as a multifunctional staging and prognosis biomarker. In this context, the oxidative state of patients may be reflected by intra- and extracellular Prx4 levels, redox state, oligomerization and nitrooxidative modifications of the enzyme. A consolidated model of the potential role and origin of circulating Prx4 is presented to stimulate further investigations in light of the current biomarker situation.
\end{abstract}

\section{Background}

Physiologically important processes such as redox signaling and host defense depend on balanced amounts of reactive oxygen species (ROS), including free radicals and stable oxidizing molecules, for example, hydrogen peroxide $\left(\mathrm{H}_{2} \mathrm{O}_{2}\right)$. In conditions of oxidative stress, increased ROS levels overwhelm antioxidant protection mechanisms, resulting in the development and progression of various diseases [1].

Peroxiredoxin 4 (Prx4; synonyms: AOE372, TRANK) is a ubiquitously expressed member of the peroxiredoxin family that is localized in the endoplasmic reticulum

Correspondence: janin.schulte@thermofisher.com

Department of Research and Development, BRAHMS GmbH, Part of Thermo Fisher Scientific, 16761 Hennigsdorf, Germany
(ER) and extracellular space $[2,3]$, with highest expression in the pancreas, liver and heart, and lowest expression in blood leukocytes and the brain $[2,4]$. The enzyme diminishes oxidative stress by reducing hydrogen peroxide to water in a thiol-dependent catalytic cycle [5] and has been linked to the regulation of the key pro-inflammatory transcription factor, nuclear factor kappa B $(\mathrm{NF}-\kappa \mathrm{B})[2,4,6]$. In addition, redox-dependent and reversible conversion of homologous Prx1-4 from disulfide-linked homodimers to higher-order multimers and back provides a versatile mechanism to switch between peroxidase and chaperone activity, enabling interaction with binding partners including stressresponsive kinases, membrane proteins and immunemodulators, fine-tuning of $\mathrm{H}_{2} \mathrm{O}_{2}$ signaling [7] and, as published most recently, circadian clock oscillations [8]. Disturbances in the aforementioned fundamental processes clearly result in numerous pathological conditions that could potentially be reflected by the measurement of involved Prx.

Among the six Prx isoforms in mammals, Prx4 emerges as the most attractive, easily accessible biomarker candidate as it was initially designated as a secretable peroxidase $[2,9]$, has recently been identified in the circulation of healthy and diseased individuals $[10,11]$ and, finally, has been linked to morbidity and mortality in patients with sepsis in the intensive care unit and patients with non-specific complaints in the emergency department [12,13]. In addition, several studies have shown that the expression or oxidation state of Prx 4 changes under pathological conditions such as cancer [14-20], diabetes [21-23] and infection [4,6,24-27].

Fast evolving genomic and proteomic studies constantly provide many new biomarker candidates, unavoidably lacking a differentiated evaluation of single candidates and possibly misdirecting promising fields of application. Hence, this commentary intends to discuss the available data on Prx4 at an early stage, focusing on the relevant clinical evidence that indicates strong 
biomarker potential in a number of conditions in critical care and the emergency room.

\section{Discussion}

\section{Clinical significance of Prx4 detection}

Prx4 should be of special interest to clinicians as it may represent a new marker candidate that could be highly valuable in predicting the prognosis of an adverse outcome to risk stratify patients and to monitor therapy. Indeed, serum and expression levels, as well as posttranslational modifications, of the enzyme have been linked to a number of different diseases, ranging from primary care to advanced critical care topics (see Additional file 1). The biomarker performance of Prx4 in these patients is truly encouraging, given the high heterogeneity and potential confounders, such as co-morbidities and medication. Indeed, Prx4 expression in the mouse liver was responsive to different drugs, including the analgesic paracetamol and the chemotherapeutic etoposide phosphate [28]. Altogether, Prx4 is assumed to be important in many single settings, which is very promising, but requires further validation. The results found by Chang and colleagues [10], for instance, are methodologically questionable because they are based on an immunoassay that worked with diluted patient plasma directly coated to the solid phase, which strongly limits specific antibody binding. Moreover, findings from different cancer studies are in part contradictory, concluding either good $[16,18]$ or bad prognosis $[14,19]$ from increased Prx4 expression in tumor tissue. Specifically, sepsis [29], cancer [30] and cardiovascular disease [31] are candidate diseases where Prx4 measurement may be of particular use as they share redox and inflammatory dysregulation and frequently lack valid severity and risk assessment by non-invasive biomarkers.

\section{Perspectives for Prx4 testing methods}

An improved understanding of the redox regulation, structural assembly and activity of Prx4 would provide a better insight into analyzing Prx4 as a biomarker in tissue or serum. Conoidin A, a specific Prx activity inhibitor, is currently under evaluation [32]. Tavender and Bulleid found Prx4 oxidation to be indicative of the degree of oxidative stress in the ER [3]. Atherosclerotic plaque development (Full et al., unpublished data), viral infection of A549 lung adenocarcinoma epithelial cells [25] and stimulation of human umbilical vein endothelial cells (HUVEC) with $\mathrm{H}_{2} \mathrm{O}_{2}$ and hydroperoxides [33] resulted in oxidation and a shifted isoelectric point of Prx4, respectively. Moreover, selective changes for either a putative $31-\mathrm{kDa}$ precursor or $27-\mathrm{kDa}$ secretable Prx4 have been reported in lung cancer [34] and spermatogenesis disorders [35,36]. Consequently, detection of Prx4 hyperoxidation and oligomerization $[3,25,37,38]$ could be a meaningful, albeit challenging, measure of thiol-redox imbalances and should be integrated into Prx4 analysis. Existing expression data, however, require careful interpretation in light of a newly discovered 29.5-kDa splice variant of Prx4 [39] that cannot be recognized by the antibodies used in the immunoassay that has been developed for the detection of Prx4 dimers and oligomers in serum [11].

\section{Origin and drivers of circulating Prx4}

The amount of secreted Prx4 is most likely proportional to the initial intracellular expression levels. With exceptions [40], it has been shown in different in vivo models of infection that Prx4 expression was further potentiated in organs with strong endogenous expression of the enzyme $[26,41]$. Consequently, tissue with high basal or up-regulated cellular expression of Prx4 likely represents a source for circulating Prx4 (Figure 1). Okado-Matsumoto and colleagues hypothesized that the enzyme is bound to the endothelial cells of blood vessels and released in response to a changed redox environment [9], matched by the high expression of Prx4 in endothelial cells [2]. There is sufficient further evidence that augmented Prx4 serum levels may be a result of secretion in response to pro-oxidant and pro-inflammatory signaling cascades, possibly related to regulation of NF$\kappa \mathrm{B}[2,4,6]$ (Figure 1). Indeed, Prx4 serum levels are correlated with endogenous antioxidants (albumin, bilirubin) and markers of inflammation (C-reactive protein, interleukin-6) in critically ill patients [13]. Moreover, changes in Prx4 expression or oxidation resulted from viral infection [4,6,24-27] and oxidative stimulation $[33,38,42,43]$ in vitro and in vivo. Preliminary data from Madin-Darby canine kidney strain I cells stably transfected with Prx4 revealed a significant dose-dependent increase of $\operatorname{Prx} 4$ secretion after stimulation with $\mathrm{H}_{2} \mathrm{O}_{2}$ (Schulte et al., unpublished data). In addition, intracellular Prx4 was associated with nitrotyrosine expression in bladder and ovarian cancer $[14,16,44]$ and nitric oxidedependent regulation in stimulated macrophages [43], suggesting nitrosative stress as another promoter of Prx4 secretion. Ultimately, circulating Prx4 may originate from non-specific membrane leakage due to tissue damage and apoptotic cell death, representing a consequence of the aforementioned stress stimuli (Figure 1).

\section{Consequences of Prx4 modification}

Intracellular Prx4 is mainly localized in the ER, where it contributes to redox and disulfide regulation [3], whereas no definite function has yet been assigned for extracellular Prx4 [6,9]. Preincubation of HUVEC with reduced $\mathrm{Prx} 4$ resulted in improved cell viability after $\mathrm{H}_{2} \mathrm{O}_{2}$ treatment [9]. Protective anti-inflammatory effects have been reported for Prx4, when injected or 


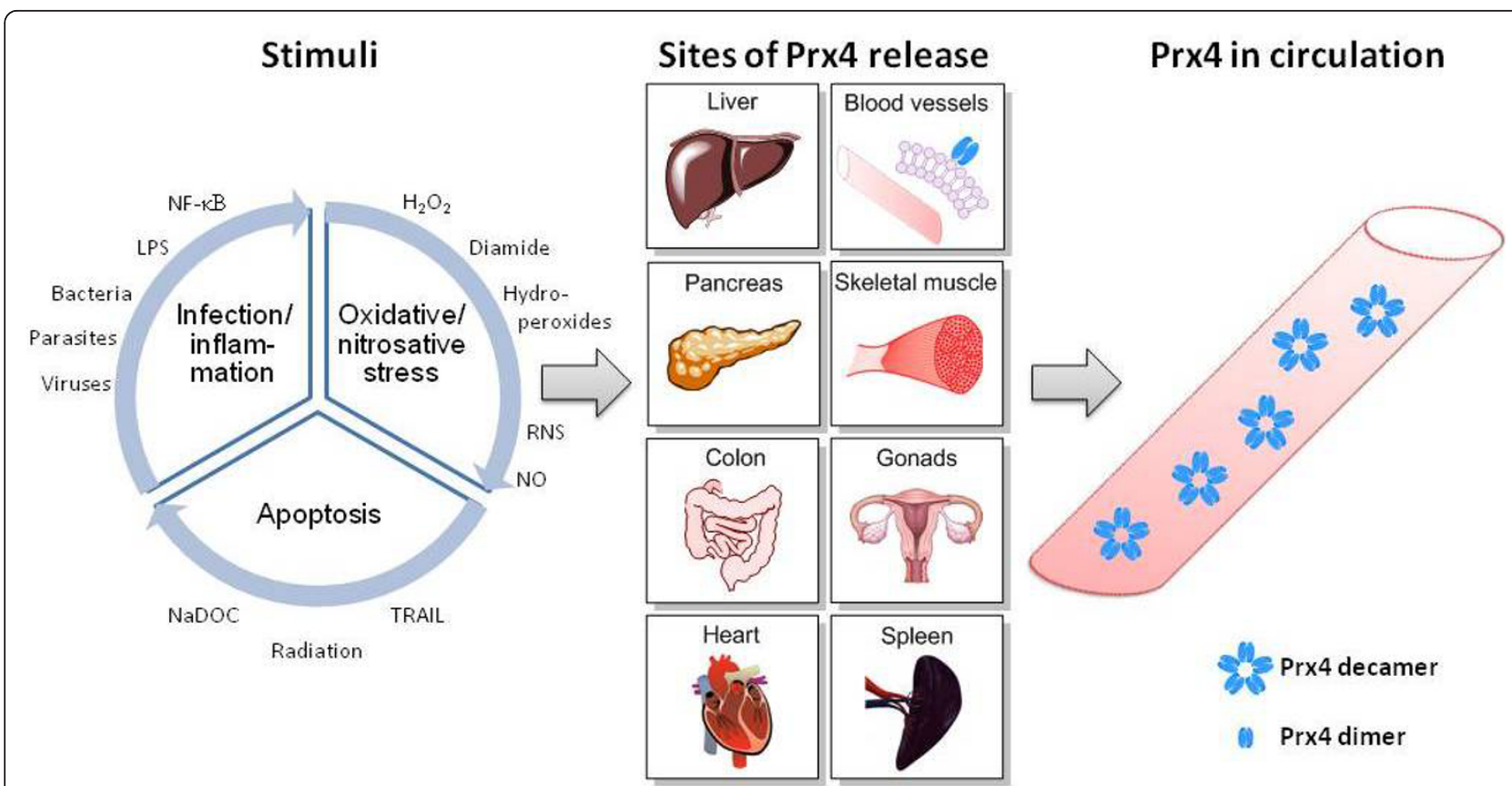

Figure 1 Potential origin and regulation of peroxiredoxin 4. Peroxiredoxin 4 (Prx4) is known to switch between dimer and pentadimeric decamer structure [3], with potential decameric structure having been identified in circulation [11]. It has been shown that Prx4 redoxdependently binds to the cell surface of human umbilical vein endothelial cells [9]. Specific and non-specific stimulation of various tissues has influenced Prx4 expression, oxidation or oligomerization and may ultimately result in secretion of Prx4. $\mathrm{H}_{2} \mathrm{O}_{2}$ : hydrogen peroxide; LPS: lipopolysaccharide; NaDOC: sodium deoxycholate; NF- $\kappa$ B: nuclear factor-kappa B; NO: nitric oxide; Prx4: peroxiredoxin 4; RNS: reactive nitrogen species; TRAIL: tumor necrosis factor-related apoptosis-inducing ligand.

overexpressed during infection $[4,6,26]$. In addition, Prx4 expression has been shown to be relevant for the antioxidant effects of natural compounds $[42,45,46]$. Chaperone activity in the extracellular space is conceivable, but requires experimental confirmation [7,47]. A recent publication by Palande and colleagues indirectly linked Prx4 to the innate immune system by showing that ER-localized Prx4 has an inhibitory effect on granulocyte colony-stimulating factor, which is a key regulator of neutrophil production [48]. However, Prx4 secretion could lead to a loss of intracellular or membrane-bound $\operatorname{Prx} 4$, which would result in a changed capacity to remove $\mathrm{H}_{2} \mathrm{O}_{2}$, to regulate redox mechanisms or to participate in signaling pathways in the cellular vicinity. The resulting cellular oxidative stress and disturbed signaling would initiate and exacerbate pathological processes, largely increasing the probability of adverse outcome and death. On this basis, a speculative model is suggested, concluding that increased serum levels of Prx4 as a result of unfavorable Prx4 translocation could indicate higher morbidity (Figure 2). Indeed, elevated Prx4 serum levels have been linked to adverse outcome and higher mortality in critical care and emergency settings $[12,13]$ as well as in the general population (Abbasi et al., unpublished data) and type 2 diabetes mellitus patients (Alkhalaf et al., unpublished data). In addition, elevated intracellular Prx4 levels in carcinoma tissue are associated with improved survival $[16,18]$, in contrast to the fact that tumor cells escape apoptosis by increased Prx4 expression [49-52]. This is in better agreement with results from other settings reporting higher mortality in cancer patients with increased Prx4 expression levels in tumor tissue $[14,19]$. Finally, there is evidence that Prx isoforms and other antioxidants can substitute for Prx4 [14,18,25,34,53], resulting in compensation for functional consequences of $\operatorname{Prx} 4$ release.

\section{Conclusions}

It seems reasonable by now to expand basic clinical research from exclusive expression studies to mechanisms of Prx4 release, oligomerization and oxidative modification in order to identify relevant biochemical interrelations and refine the actual biomarker value of Prx4. Present data indicate that Prx4, either intracellular or extracellular, has the potential to serve as a biomarker for both the early staging of disease severity and the prediction of the future disease course in different pathologies that involve dysregulation of the redox system, for example, as evident during inflammatory processes. Accordingly, it is recommended that promising results from recent studies be validated and clinical trials be performed in new indications to ultimately 

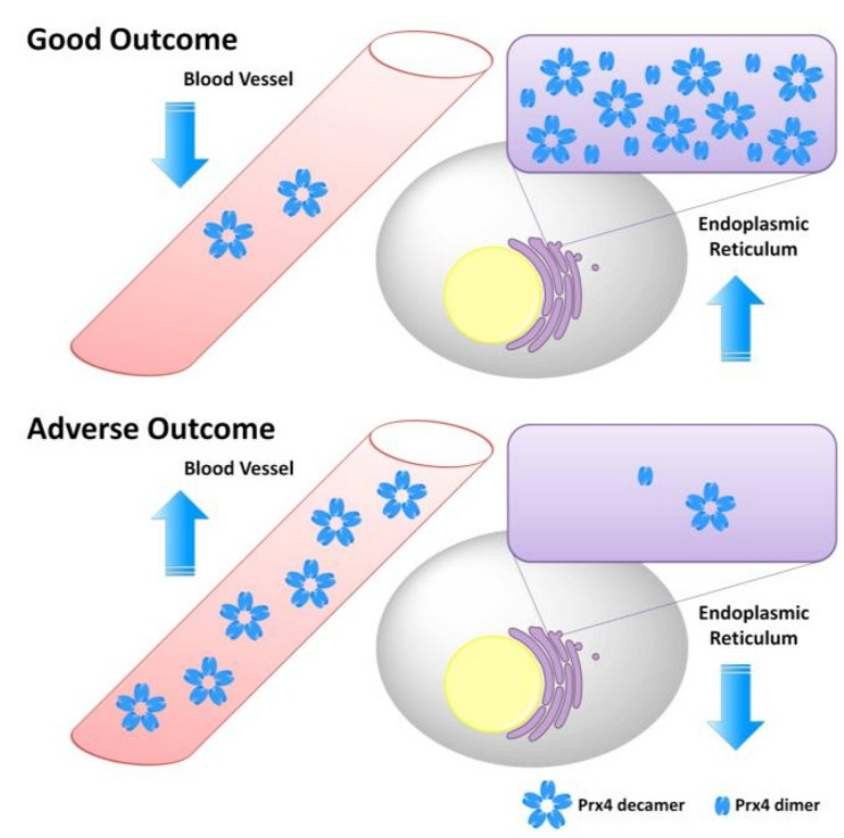

Figure 2 Speculative model of unfavorable peroxiredoxin 4 translocation. Intracellular peroxiredoxin 4 (Prx4) is localized in the endoplasmic reticulum where it switches between dimer and pentadimeric decamer structure [3]. A potential decameric structure has been proposed for extracellular Prx4 circulating in the blood [11]. A 'good outcome', that is, an improvement of or a protection against pathological processes, could be achieved by high cellular Prx4 levels. Low endogenous Prx4 serum levels, corresponding to non-secreted high intracellular Prx4 levels, imply a non-serious disease course. Accordingly, decreased intracellular Prx4 levels or elevated endogenous serum levels of the enzyme are indicative of 'adverse outcome', that is, a more severe disease course or a higher mortality rate.

assess the overall use of Prx4 for risk stratification and therapy monitoring in comparison with existing standards.

\section{Additional material}

Additional file 1: Peroxiredoxin 4 in clinical indications. This overview does not presume to be complete. Indeed, cited cancer settings are limited to subgroups with important clinical findings beyond changes in peroxiredoxin 4 expression. Unless otherwise mentioned, the term 'Prx4' refers to intracellular protein levels.

\section{Acknowledgements}

The author is indebted to Dr Joachim Struck for reviewing the manuscript.

\section{Competing interests}

JS is an employee of BRAHMS GmbH, Part of Thermo Fisher Scientific, who have developed and patented the Prx4 immunoassay.

Received: 26 August 2011 Accepted: 23 December 2011 Published: 23 December 2011

\section{References}

1. Dalle-Donne I, Rossi R, Colombo R, Giustarini D, Milzani A: Biomarkers of oxidative damage in human disease. Clin Chem 2006, 52(4):601-623.

2. Haridas V, Ni J, Meager A, Su J, Yu GL, Zhai Y, Kyaw H, Akama KT, Hu J, Van Eldik L, Aggarwal BB: TRANK, a novel cytokine that activates NF-kappa B and c-Jun N-terminal kinase. J Immunol 1998, 161(1):1-6.
3. Tavender TJ, Bulleid NJ: Peroxiredoxin IV protects cells from oxidative stress by removing $\mathrm{H} 2 \mathrm{O} 2$ produced during disulphide formation. J Cell Sci 2010, 123(Pt 15):2672-2679.

4. Jin D-Y, Chae HZ, Rhee SG, Jeang K-T: Regulatory role for a novel human thioredoxin peroxidase in NF-kB activation. J Biol Chem 1997, 272(49):30952-30961.

5. Wood ZA, Schröder E, Harris JR, Poole LB: Structure, mechanism and regulation of peroxiredoxins. Trends Biochem Sci 2003, 28(1):32-40.

6. YU S, Mu Y, Ao J, Chen X: Peroxiredoxin IV regulates pro-inflammatory responses in large yellow croaker (Pseudosciaena crocea) and protects against bacterial challenge. J Proteome Res 2010, 9(3):1424-1436.

7. Rhee SG, Woo HA: Multiple functions of peroxiredoxins: peroxidases, sensors and regulators of the intracellular messenger $\mathrm{H}_{2} \mathrm{O} 2$, and protein chaperones. Antioxid Redox Signal 2011, 15(3):781-794.

8. O'Neill JS, Reddy AB: Circadian clocks in human red blood cells. Nature 2011, 469(7331):498-503.

9. Okado-Matsumoto A, Matsumoto A, Fujii J, Taniguchi N: Peroxiredoxin IV is a secretable protein with heparin-binding properties under reduced conditions. J Biochem 2000, 127(3):493-501.

10. Chang $X$, Cui $Y$, Zong M, Zhao Y, Yan X, Chen Y, Han J: Identification of proteins with increased expression in rheumatoid arthritis synovial tissues. J Rheumatol 2009, 36(5):872-880.

11. Schulte J, Struck J, Bergmann A, Köhrle J: Immunoluminometric assay for quantification of peroxiredoxin 4 in human serum. Clin Chim Acta 2010, 411(17-18):1258-1263.

12. Nickel CH, Ruedinger J, Misch F, Blume K, Maile S, Schulte J, Köhrle J, Hartmann O, Giersdorf S, Bingisser R: Copeptin and peroxiredoxin-4 independently predict mortality in patients with nonspecific complaints presenting to the emergency department. Acad Emerg Med 2011, 18(8):851-859.

13. Schulte J, Struck J, Köhrle J, Müller B: Circulating levels of peroxiredoxin 4 as a novel biomarker of oxidative stress in patients with sepsis. Shock 2011, 35(5):460-465.

14. Soini Y, Haapasaari KM, Vaarala MH, Turpeenniemi-Hujanen T, Kärjä V, Karihtala P: 8-hydroxydeguanosine and nitrotyrosine are prognostic 
factors in urinary bladder carcinoma. Int I Clin Exp Pathol 2011, 4(3):267-275.

15. Chen G, Gharib TG, Huang CC, Thomas DG, Shedden KA, Taylor JM, Kardia SL, Misek DE, Giordano TJ, lannettoni MD, Orringer MB, Hanash SM, Beer DG: Proteomic analysis of lung adenocarcinoma: identification of a highly expressed set of proteins in tumors. Clin Cancer Res 2002, 8(7):2298-2305.

16. Karihtala P, Soini Y, Vaskivuo L, Bloigu R, Puistola U: DNA adduct 8hydroxydeoxyguanosine, a novel putative marker of prognostic significance in ovarian carcinoma. Int I Gynecol Cancer 2009, 19(6):1047-1051.

17. Karihtala P, Kauppila S, Soini Y, Jukkola-Vuorinen A: Oxidative stress and counteracting mechanisms in hormone receptor positive, triple-negative and basal-like breast carcinomas. BMC Cancer 2011, 11:262.

18. Karihtala P, Mantyniemi A, Kang SW, Kinnula VL, Soini Y: Peroxiredoxins in breast carcinoma. Clin Cancer Res 2003, 9(9):3418-3424.

19. Chang KP, Yu JS, Chien KY, Lee CW, Liang Y, Liao CT, Yen TC, Lee LY, Huang LL, Liu SC, Chang YS, Chi LM: Identification of PRDX4 and P4HA2 as metastasis-associated proteins in oral cavity squamous cell carcinoma by comparative tissue proteomics of microdissected specimens using iTRAQ technology. J Proteome Res 2011, 10(11):4935-4947.

20. Basu A, Banerjee H, Rojas H, Martinez SR, Roy S, Jia Z, Lilly MB, De León M, Casiano CA: Differential expression of peroxiredoxins in prostate cancer: consistent upregulation of PRDX3 and PRDX4. Prostate 2011, 71(7):755-765.

21. Dreja T, Jovanovic Z, Rasche A, Kluge R, Herwig R, Tung YC, Joost HG, Yeo GS, Al-Hasani H: Diet-induced gene expression of isolated pancreatic islets from a polygenic mouse model of the metabolic syndrome. Diabetologia 2010, 53(2):309-320.

22. Jiang $Y L$, Ning $Y$, Ma $X L$, Liu YY, Wang $Y$, Zhang Z, Shan $C X$, Xu YD, Yin LM, Yang YQ: Alteration of the proteome profile of the pancreas in diabetic rats induced by streptozotocin. Int J Mol Med 2011, 28(2):153-160.

23. Xie X, Li S, Liu S, Lu Y, Shen P, Ji J: Proteomic analysis of mouse islets after multiple low-dose streptozotocin injection. Biochim Biophys Acta 2008, 1784(2):276-284.

24. Wang X, Zhang S, Sun C, Yuan ZG, Wu X, Wang D, Ding Z, Hu R: Proteomic profiles of mouse neuro n2a cells infected with variant virulence of rabies viruses. J Microbiol Biotechnol 2011, 21(4):366-373.

25. Jamaluddin M, Wiktorowicz JE, Soman KV, Boldogh I, Forbus JD, Spratt H, Garofalo RP, Brasier AR: Role of peroxiredoxin 1 and peroxiredoxin 4 in protection of respiratory syncytial virus-induced cysteinyl oxidation of nuclear cytoskeletal proteins. J Virol 2010, 84(18):9533-9545.

26. Knight M, Raghavan N, Goodall C, Cousin C, Ittiprasert W, Sayed A, Miller A, Williams DL, Bayne CJ: Biomphalaria glabrata peroxiredoxin: effect of Schistosoma mansoni infection on differential gene regulation. Mol Biochem Parasitol 2009, 167(1):20-31.

27. Mota S, Mendes M, Freitas N, Penque D, Coelho AV, Cunha C: Proteome analysis of a human liver carcinoma cell line stably expressing hepatitis delta virus ribonucleoproteins. J Proteomics 2009, 72(4):616-627.

28. Young R, Hayes JD, Brown K, Wolf CR, Whitelaw CB: Peroxiredoxin gene expression signatures in liver reflect toxic insult. Assay Drug Dev Technol 2010, 8(4):512-517.

29. Anderson R, Schmidt R: Clinical biomarkers in sepsis. Front Biosci (Elite Ed) 2010, 2:504-520.

30. Reuter S, Gupta SC, Chaturvedi MM, Aggarwal BB: Oxidative stress, inflammation, and cancer: how are they linked? Free Radic Biol Med 2010, 49(11):1603-1616.

31. Uno K, Nicholls SJ: Biomarkers of inflammation and oxidative stress in atherosclerosis. Biomark Med 2010, 4(3):361-373.

32. Liu G, Botting CH, Evans KM, Walton JAG, Xu G, Slawin AMZ, Westwood NJ: Optimisation of conoidin A, a peroxiredoxin inhibitor. Chem Med Chem 2010, 5:41-45.

33. Mitsumoto A, Takanezawa Y, Okawa K, Iwamatsu A, Nakagawa Y: Variants of peroxiredoxins expression in response to hydroperoxide stress. Free Radic Biol Med 2001, 30(6):625-635.

34. Lehtonen ST, Svensk AM, Soini Y, Paakko P, Hirvikoski P, Kang SW, Saily M, Kinnula VL: Peroxiredoxins, a novel protein family in lung cancer. Int $J$ Cancer 2004, 111(4):514-521.

35. Huo R, He Y, Zhao C, Guo X-J, Lin M, Sha J-H: Identification of human spermatogenesis-related proteins by comparative proteomic analysis: a preliminary study. Fertil Steril 2008, 90(4):1109-1118.
36. Matsuki S, Sasagawa I, luchi Y, Fujii J: Impaired expression of peroxiredoxin 4 in damaged testes by artificial cryptorchidism. Redox Rep 2002, 7(5):276-278

37. Ikeda $Y$, Ito $R$, Ihara $H$, Okada T, Fujii J: Expression of $\mathrm{N}$-terminally truncated forms of rat peroxiredoxin-4 in insect cells. Protein Expr Purif 2010, 72(1):1-7.

38. O'Flaherty C, Rico de Souza A: Hydrogen peroxide modifies human sperm peroxiredoxins in a dose-dependent manner. Biol Reprod 2011, 84(2):238-247.

39. Yim SH, Kim YJ, Oh SY, Fujii J, Zhang Y, Gladyshev VN, Rhee SG: Identification and characterization of an alternatively transcribed form of peroxiredoxin IV that is specifically expressed in spermatids of the postpubertal mouse testis. J Biol Chem 2011, 286(45):39002-39012.

40. Pérez-Sánchez J, Bermejo-Nogales A, Calduch-Giner JA, Kaushik S, SitjàBobadilla A: Molecular characterization and expression analysis of six peroxiredoxin paralogous genes in gilthead sea bream (Sparus aurata): insights from fish exposed to dietary, pathogen and confinement stressors. Fish Shellfish Immunol 2011, 31(2):294-302.

41. Qiu L, Ma Z, Jiang S, Wang W, Zhou F, Huang J, Li J, Yang Q: Molecular cloning and mRNA expression of peroxiredoxin gene in black tiger shrimp (Penaeus monodon). Mol Biol Rep 2010, 37(6):2821-2827.

42. Hazane-Puch F, Benaraba R, Valenti K, Osman M, Laporte F, Favier A, Anderson RA, Roussel AM, Hininger-Favier I: Chromium III histidinate exposure modulates gene expression in $\mathrm{HaCaT}$ human keratinocytes exposed to oxidative stress. Biol Trace Elem Res 2010, 137(1):23-39.

43. Diet A, Abbas K, Bouton C, Guillon B, Tomasello F, Fourquet S, Toledano MB, Drapier JC: Regulation of peroxiredoxins by nitric oxide in immunostimulated macrophages. J Biol Chem 2007, 282(50):36199-36205.

44. Pylväs M, Puistola U, Kauppila S, Soini Y, Karihtala P: Oxidative stressinduced antioxidant enzyme expression is an early phenomenon in ovarian carcinogenesis. Eur J Cancer 2010, 46(9):1661-1667.

45. Hayder N, Bouhlel I, Skandrani I, Kadri M, Steiman R, Guiraud P, Mariotte AM, Ghedira K, Dijoux-Franca MG, Chekir-Ghedira L: In vitro antioxidant and antigenotoxic potentials of myricetin-3-o-galactoside and myricetin-3-o-rhamnoside from Myrtus communis: modulation of expression of genes involved in cell defence system using CDNA microarray. Toxicol In Vitro 2008, 22(3):567-581.

46. Hansen J, Palmfeldt J, Vang S, Corydon TJ, Gregersen N, Bross P: Quantitative proteomics reveals cellular targets of celastrol. PLoS One 2011, 6(10):e26634.

47. Yerbury JJ, Stewart EM, Wyatt AR, Wilson MR: Quality control of protein folding in extracellular space. EMBO Rep 2005, 6(12):1131-1136.

48. Palande K, Roovers O, Gits J, Verwijmeren C, luchi Y, Fujii J, Neel BG, Karisch R, Tavernier J, Touw IP: Peroxiredoxin-controlled G-CSF signalling at the endoplasmic reticulum-early endosome interface. J Cell Sci 2011, 124(Pt 21):3695-3705.

49. Park JJ, Chang HW, Jeong EJ, Roh JL, Choi SH, Jeon SY, Ko GH, Kim SY: Peroxiredoxin IV protects cells from radiation-induced apoptosis in head-and-neck squamous cell carcinoma. Int I Radiat Oncol Biol Phys 2009, 73(4):1196-1202.

50. Wang HQ, Du ZX, Liu BQ, Gao YY, Meng X, Guan Y, Zhang HY: TNF-related apoptosis-inducing ligand suppresses PRDX4 expression. FEBS Lett 2009, 583(9):1511-1515.

51. Crowley-Weber CL, Payne CM, Gleason-Guzman M, Watts GS, Futscher B, Waltmire CN, Crowley C, Dvorakova K, Bernstein C, Craven M, Garewal H, Bernstein H: Development and molecular characterization of HCT-116 cell lines resistant to the tumor promoter and multiple stress-inducer, deoxycholate. Carcinogenesis 2002, 23(12):2063-2080.

52. Lee YS, Chang HW, Jeong JE, Lee SW, Kim SY: Proteomic analysis of two head and neck cancer cell lines presenting different radiation sensitivity. Acta Otolaryngol 2008, 128(1):86-92.

53. Shen C, Nathan C: Nonredundant antioxidant defense by multiple twocysteine peroxiredoxins in human prostate cancer cells. Mol Med 2002, 8(2):95-102.

\section{Pre-publication history}

The pre-publication history for this paper can be accessed here: http://www.biomedcentral.com/1741-7015/9/137/prepub

doi:10.1186/1741-7015-9-137

Cite this article as: Schulte: Peroxiredoxin 4: a multifunctional biomarker worthy of further exploration. BMC Medicine 2011 9:137. 